\title{
Associations between psychometrically assessed life history strategy and daily behavior: Data from the Electronically Activated Recorder (EAR)
}

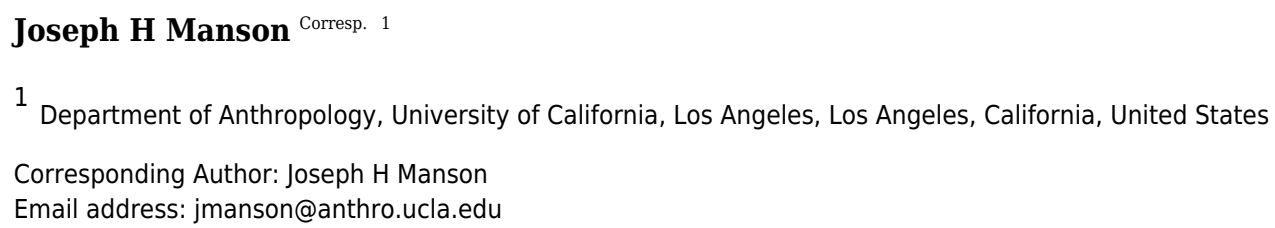

Life history theory has generated cogent, well-supported hypotheses about individual differences in human biodemographic traits (e.g. age at sexual maturity) and psychometric traits (e.g. conscientiousness), but little is known about how variation in life history strategy (LHS) is manifest in quotidian human behavior. Here I test predicted associations between the self-report Arizona Life History Battery and frequencies of 12 behaviors observed over 72 hours in 91 U.S. college students using the Electronically Activated Recorder (EAR), a method of gathering periodic brief audio recordings as participants go about their daily lives. Bayesian multi-level aggregated binomial regression analysis found no strong associations between ALHB scores and behavior frequencies. One behavior, presence at amusement venues (bars, concerts, sports events) was weakly positively associated with ALHB-assessed slow LHS, contrary to prediction. These results may represent a challenge to the ALHB's validity. However, it remains possible that situational influences on behavior, which were not measured in the present study, moderate the relationships between psychometrically-assessed LHS and quotidian behavior. 
1 Associations between psychometrically assessed life history

2 strategy and daily behavior: data from the Electronically

3 Activated Recorder (EAR)

4 Joseph H. Manson ${ }^{1}$

$5 \quad{ }^{1}$ Department of Anthropology, University of California, Los Angeles, California, United States

6

7 Corresponding Author:

8 Joseph H. Manson

9 Department of Anthropology, UCLA, 341 Haines Hall, Box 951553, Los Angeles, CA, 90095-

10 1553, United States

11 Email address: jmanson@anthro.ucla.edu

12 


\section{Abstract}

14

15

Life history theory has generated cogent, well-supported hypotheses about individual differences in human biodemographic traits (e.g. age at sexual maturity) and psychometric traits (e.g. conscientiousness), but little is known about how variation in life history strategy (LHS) is manifest in quotidian human behavior. Here I test predicted associations between the self-report Arizona Life History Battery and frequencies of 12 behaviors observed over 72 hours in 91 U.S. college students using the Electronically Activated Recorder (EAR), a method of gathering periodic brief audio recordings as participants go about their daily lives. Bayesian multi-level aggregated binomial regression analysis found no strong associations between ALHB scores and behavior frequencies. One behavior, presence at amusement venues (bars, concerts, sports events) was weakly positively associated with ALHB-assessed slow LHS, contrary to prediction. These results may represent a challenge to the ALHB's validity. However, it remains possible that situational influences on behavior, which were not measured in the present study, moderate the relationships between psychometrically-assessed LHS and quotidian behavior. 


\section{Introduction}

Life History Theory (LHT) describes and explains evolutionary processes that shape organisms' allocations of energy among the competing demands of growth, bodily maintenance, and reproduction (including courtship and parental investment) (MacArthur \& Wilson, 1967; Pianka, 1970). On both phylogenetic and ontogenetic time scales, age-specific extrinsic mortality rates are a major driver of variation in Life History Strategy (LHS), such that higher extrinsic mortality rates select for a "faster" LHS, which prioritizes reproductive effort over somatic (i.e. growth and maintenance) effort, mating effort over parenting effort, and offspring quantity over offspring quality (Charnov, 1993; Stearns, 1992). Lower extrinsic mortality rates select for a "slower" LHS, which prioritizes the opposite energy allocations.

A large body of research, building on the seminal work of Rushton (1985) and Belsky, Steinberg \& Draper (1991) has used LHT to generate and test hypotheses about human individual and group differences. Three general approaches are distinguishable. First, research into the biodemographic aspects of LHS variation explores environmental influences on LH traits such as growth rates, age at first reproduction, and interbirth intervals. For example, in a multivariate analysis of a sample of small-scale societies, indicators of greater food availability were associated with faster and earlier child growth, but higher survival rates were associated with slower and later development (Walker et al., 2006). Among British neighborhoods, greater deprivation was associated with lower healthy life expectancy, earlier age at first birth, and shorter breastfeeding duration (Nettle, 2010). Second, researchers have examined whether, under laboratory conditions, LHT-related individual differences predict differences in responses to theoretically specified stimuli. For example, some findings indicate that low childhood socioeconomic status (cueing a faster LHS) interacts with mortality-risk primes to increase riskproneness and reward delay discounting (Griskevicius et al., 2011; but see Pepper et al., 2017). Third, the psychometric approach to understanding LHS variation has posited theory-based cognitive and behavioral manifestations of LHS, and has explored (1) their cohesion as a latent LH factor and (2) the relationships between this factor and various predictor and criterion variables (e.g. Chua et al., 2017; Dunkel \& Decker, 2010; Figueredo et al., 2004; Figueredo et al., 2005; Figueredo et al., 2007; Figueredo et al., 2015; but see Richardson et al., 2017 for an alternative view). This research tradition uses self-report measures of constructs such as the major dimensions of personality, attachment style, positive and negative affect, paranoia, and general trust. A slower LHS is associated with higher levels of conscientiousness, agreeableness and emotional stability; a secure attachment style; more positive affect; less negative affect; greater religiosity; and a more prosocial orientation toward conspecifics.

A still largely unexplored set of questions concerns the relationships between LHS, as a highlevel psychological construct, and quotidian behavior measured via direct observation. In other words, little has been done to describe the ethology of human LHS variation (but see Sherman, Figueredo \& Funder, 2013). For example, do faster and slower LH strategists differ in how they allocate their time across activities, or in how they conduct face-to-face interactions with friends, romantic partners, or colleagues? These questions are important for three reasons. First, the 
understanding of individual differences, from any theoretical perspective, can be greatly enriched by studying naturally occurring behavior in addition to self-report ratings and laboratory task responses (Funder, 2001; Furr, 2009). Second, answers to these questions will suggest the extent to which human LHS is detectable to intimate, or even casual, observers, and they may provide a foundation for hypotheses about adaptations for detecting LHS in others. Given that personality variation is one manifestation of LHS variation (Figueredo et al., 2007; Manson, 2017a; Rushton, 1985), and that personality is somewhat detectable from casual observation (Funder, 2012), this is a potentially fruitful line of inquiry. Third, an ethology of LHS will help bridge the gap between traditional evolutionary psychology and differential evolutionary psychology (see Buss, 2009). The former emphasizes species-typical, semi-autonomous, domain-specific modules (Tooby \& Cosmides, 1990), whereas the latter emphasizes evolutionary processes (e.g. balancing selection, mutation-selection balance) that generate and maintain individual variation in domain-specific reaction norms (e.g. Nettle \& Penke, 2010; Verweij et al., 2012). According to LH theory, these reaction norms governing different domains are inter-correlated rather than independent (Del Giudice, 2014; Figueredo et al., 2013). Individuals differ in their "settings" of LH-related species-typical modules (e.g. risk-proneness), and these differences can be probed by experiments (e.g. Griskevicius et al., 2011). However, natural selection has likely acted on individual differences in situation selection (Buss, 1987; de Vries et al., 2016; Nettle \& Penke, 2010) - for example, people differ in their self-chosen exposure to situations in which risk-taking is salient. Merely knowing how a person responds to a laboratory manipulation reveals nothing about such variation. Furthermore, different situations afford the expression of different personality traits (Reis, 2008) - for example, it's much easier to express extraversion at a party than while writing a manuscript. These issues can only be explored by systematic observation of naturally occurring behavior, using theory-driven behavioral categorization.

\section{The present study}

As a preliminary inquiry into the ethology of LHS variation, I address a simple question: how well does a widely-used psychometric LHS instrument, the Arizona Life History Battery (ALHB: Figueredo, 2007) predict the everyday behavior of a sample of U.S. college students? The ALHB, or its short form the Mini-K, has been used in many studies (Figueredo et al., 2015), but almost all of this work describes associations with other self-report instruments. A possible weakness of the ALHB/Mini-K is its undercoverage of aspects of extraversion (dominance striving, sensation-seeking) and openness to experience (imagination, unconventionality) that are theoretically expected (Del Giudice, 2014) to be associated with a faster LHS. In earlier analyses of the data set used in this paper (Manson, 2017a), self-reported ALHB scores were found to be only weakly (non-significantly) associated with other-reported LHS as indicated by similarity to the slow life history template (Dunkel et al., 2015; Sherman, Figueredo \& Funder, 2013) of the California Adult Q-Sort (CAQ: Block, 1978). Analysis of this template indicates that it taps the fast LHS-associated facets of extraversion and openness (Manson, 2017a). Furthermore, the slow LHS template of the CAQ has been validated by correlating it with biodemographic LH indicators such as age at sexual debut and number of sex partners (Dunkel et al., 2015; see also Kubinski, Chopik \& Grimm, 2017). 
In the present study, participants' everyday behavior was sampled using the Electronically Activated Recorder (EAR: Mehl et al., 2001; Mehl \& Robbins, 2012). The EAR unobtrusively collects periodic brief audio snippets of people's daily lives, using a portable recording device that participants wear attached to their clothes during their waking hours. Behavioral variables coded from EAR recordings (e.g. location and general activity) have shown substantial interrater reliability and within-participant temporal stability (Mehl \& Pennebaker, 2003), and have provided novel insights into processes such as parent-child transmission of negative emotionality (Slatcher \& Trentacosta, 2012) and the role of family environment in children's recovery from trauma (Alisic et al, 2015). Self-reported major personality dimensions are correlated in predictable ways with some EAR-measured variables (e.g. extraversion negatively correlated with proportion of time spent alone; Mehl, Gosling \& Pennebaker, 2006).

Table 1 lists the behaviors measured in the present study, and their predicted associations with slow life history strategy as measured by the ALHB, based on findings from psychometric studies (Brumbach, Figueredo \& Ellis, 2009; Figueredo et al. 2007; Figueredo et al. 2005; Figueredo et al. 2014a; Sherman, Figueredo \& Funder, 2013). College students pursuing a slower LHS were predicted to engage more frequently in behavior indicative of (1) future time perspective, the ability to learn from past experience, and investment in embodied capital (Kaplan et al., 2000) (class attendance, talking about long-term plans and talking about past experiences), (2) altruistic dispositions toward kin and the wider community (talking to kin; talking about kin; volunteering); and (3) religiosity (attending religious services and study groups). A slower LHS was predicted to be associated with lower rates of (1) entertainment consumption (TV and movie watching; videogame playing; being at amusement venues such as bars, concerts, and sports events), (2) talk endorsing alcohol or recreational drug use, (3) indicators of negative affect (general complaining; sighing; see Robbins et al., 2011; Roth, 2005), and (4) indicators of antagonistic social schemata (Patch \& Figueredo, 2017) or an alienated social orientation (arguing; complaining about authority figures). A final prediction, that a slower LHS would be negatively related to amount of daytime sleeping, requires additional explanation. Research suggests that LHS is related to chronotype (morningness/eveningness, Adan et al., 2012), such that people pursuing a slower LHS are more active in the morning, whereas those pursuing a faster LHS are more active in the evening (Ponzi et al., 2015). Because the audio recording protocol in the present study included an 00:00-06:00 blackout period (see Materials and Methods), and because participants rarely went to sleep before the blackout period began (see Results), sleeping time mostly consisted of sleeping between 06:00 and 18:00. Sleep time during this time interval (corresponding to late rising and afternoon napping) was isolated for analysis, and I tested the prediction that it would be negatively associated with a slower LHS.

Finally, because the ALHB/Mini-K is strongly positively related to extraversion (Figueredo et al., 2014a; Gladden, Figueredo \& Jacobs, 2009; Manson, 2015; Strouts, Brase \& Dillon, 2016), including among the present study's participants (Manson, 2017a), ALHB scores were predicted to be positively associated with two indicators of sociality (engagement in social interaction; proportion of social interactions that involve more than one interlocutor). 


\section{Ethics statement}

All procedures described here were approved by UCLA's Institutional Review Board (Approval \#12-001128-AM-00001). Informed consent was obtained from all participants in accordance with the terms of this approval.

\section{Relation to previous research}

The dataset used in the present study is the same as that used by Manson (2017a; 2017b) and Manson \& Robbins (2017), but the analyses reported here are novel.

\section{Participants}

Ninety-two students (55.4\% female, $M \pm S D=20.0 \pm 3.1$ years old), enrolled at the University of participate in a study bearing the public title "Audio Sampling of Daily Life." Based on selfreported ethnic identity, 53.2\% of the sample was Asian or Asian-American, 16.3\% White, 12.0\% Latino/a, 3.2\% Middle Eastern, and 15.3\% mixed or "other." Although unrepresentative of college-aged Americans generally, the sample's ethnic composition was fairly representative of UCLA's undergraduate student body. Data were collected between October 2013 and January 2015 .

\section{Procedure}

Audio sampling

Recordings were made using the Electronically Activated Recorder (EAR: Mehl et al., 2001; Mehl, Robbins \& grosse Deters, 2012). Instantiated as an app for the iPod Touch, the EAR generates periodic brief audio recordings (in this study, a 30-sec clip every $12.5 \mathrm{~min}$ ) as participants go about their daily lives. Participants know the general sampling pattern, but not whether the app is recording at any particular time. In the present study, participants were instructed to wear the iPod clipped to their belt or waistline whenever possible during their waking hours for a 72-hour period. Recording could begin on any weekday. No recordings were made between midnight and 0600. Participants were also instructed to keep an hourly diary briefly describing their general activities and whether or not they were wearing the iPod during that entire hour. Upon returning the iPod, participants were given the opportunity to privately review their audio clips and to delete any they wished, before researchers listened to them. Participants received a $\$ 50$ Amazon gift card as compensation. They were not informed of the specific hypotheses motivating the study until after all participants had completed participation. 
188

189

190

191

192

193

194

195

196

197

198

199

200

201

202

203

204

205

206

207

208

209

210

211

212

213

214

215

216

217

218

219

220

221

222

223

224

225

226

227

\section{Self-report measures}

After returning the iPod and before receiving their compensation, participants were asked to complete, at their convenience, an online battery of self-report instruments, including the ALHB (Figueredo, 2007), a 199-item instrument consisting of eight scales drawn from various original sources (Barrera, Sandler \& Ramsay, 1981; Brennan, Clark \& Shaver, 1998; Brim et al., 2000). Seven of the scales measure distinct aspects of life history strategy: insight, planning and control; relationships with biological parents; family contact and support; friends contact and support; general altruism; religiosity; and experiences in close relationships. The eighth ALHB scale, the Mini- $K$, contains 20 items tapping general features of all seven LHS facets. Because the sample was drawn from an undergraduate population, I deleted from analyses the 8 items of the ALHB's altruism toward children subscale. The eight ALHB indicators converge on a single multivariate latent construct, the K-Factor (Gladden, Figueredo \& Jacobs, 2009; Wenner et al., 2013), which can be estimated as the mean of the $z$-scores of the seven scales excluding the Mini- $K$ (Figueredo, 2007). Higher K-Factor scores indicate a slower LHS.

\section{Data preparation and analysis}

\section{EAR behavior coding}

Each audio clip was coded by a trained research assistant with respect to 31 behavioral variables, including two that were measured to assess effects of the EAR method itself on behavior:

compliance, i.e. whether the iPod was on the participant's person, or at least close enough to generate valid recordings; and talk about participating in the study, as a measure of obtrusiveness. Results indicating acceptably high compliance and low obtrusiveness are presented by Manson \& Robbins (2017). Of the remaining 29 behaviors, 18 are relevant to the present study (Table 1).

Each participant's clips were coded by one coder. Inter-rater reliability was assessed by assigning the 11 research assistants to code a test set of 110 clips containing at least one exemplar of every coded behavior category. Research assistants coded these clips independently, and inter-rater reliability was measured with Cohen's kappa. A kappa value of .41 (moderate agreement according to Landis \& Koch, 1977) was pre-selected as the cut-off below which variables would be excluded from further analysis.

\section{Modeling relationships between predictor variables and behavior frequencies}

To assess relationships between the ALHB and behavior frequencies, I carried out Bayesian multi-level aggregated binomial regressions, using inferential procedures and notation described by McElreath (2015). Previous EAR-based research (e.g. Baddeley, Pennebaker \& Beevers, 2013; Mehl, Gosling \& Pennebaker, 2006) has scored behavioral variables as proportions, e.g. the number of a participant's audio clips containing dyadic interactions divided by the total number of that participant's clips containing interactions (dyadic plus larger conversational groups). However, converting count data to proportions or percentages discards the information contained in the magnitude of the denominator; e.g. the observation that one participant's multiinterlocutor social interactions comprised 10 out of 20 clips containing any social interaction is less reliable (contains less information) than the observation that another participant's multi- 
228

229

230

231

232

233

234

235

236

237

238

239

240

241

242

243

244

245

246

247

248

249

250

251

252

253

254

255

256

257

258

259

260

$\alpha_{\text {PARTICIPANT }} \sim$ HalfCauchy $(0,1)$ follows:

$\alpha \sim \operatorname{Normal}(0,2)$

$\beta \sim \operatorname{Normal}(0,2)$

$\alpha_{\text {PARTICIPANT[i] }} \sim \operatorname{Normal}\left(0, \sigma_{\text {PARTICIPANT }}\right)$

interlocutor interactions comprised 60 out of 120 clips containing any interaction. A binomial regression procedure models the observed (count) form of the data as a binary outcome (here, whether a particular behavior does or does not occur in a particular audio clip). A multi-level binomial regression, using participants as clusters, estimates both an overall intercept (here, the probability of a behavior occurring in a clip when the predictor variable[s] is at its mean value) and a specific intercept for each participant. Thus, the model takes into account (1) unmeasured differences between participants that are related to the occurrence of the designated behavior, (2) the additional uncertainty introduced by rarely occurring behaviors, and (3) skewed distributions of behavior frequencies. Estimates of participant-specific intercepts that are farther from the overall intercept, and/or based on a smaller denominator (i.e. the number of clips in which the behavior could possibly have occurred), are "shrunk" farther toward the overall intercept. These intercepts are then incorporated into a linear model of the relationship between the predictor (here, the LHS or personality measure) and the probability of a behavior occurring during a given clip. A logit link maps this probability (which must lie between 0 and 1 ) onto a linear model (in which the outcome variable is expressed as log-odds). Rather than a $p$-value, each Bayesian model yields a posterior distribution of parameter value combinations, i.e. the relative probability of having generated the observed data associated with each combination of intercept, "slope" (i.e. the relationship between the predictor variable and the probability of engaging in that behavior), and standard deviation of the outcome variable. As an example, the relationship between ALHB score and the frequency of multi-interlocutor social interactions was modeled as

Count-of-multi-interlocutor-interactions $\mathrm{i}_{\mathrm{i}} \sim \operatorname{Binomial}\left(n_{\mathrm{i}}, p_{\mathrm{i}}\right)$

$\operatorname{logit}\left(p_{\mathrm{i}}\right)=\alpha+\alpha_{\text {PARTICIPANT }[\mathrm{i}]}+\left(\beta * \mathrm{ALHB}_{\mathrm{i}}\right)$ 
Line (1), the likelihood, states that the number of clips containing multi-interlocutor interactions involving participant $i$ is distributed binomially, with $n_{\mathrm{i}}$ as the total number of $i$ 's clips containing any social interactions, and $p_{\mathrm{i}}$ as the probability that a clip containing social interaction by participant $i$ contains a multi-interlocutor interaction. Line (2) is the logit link function, incorporating the overall intercept, the participant-specific intercept offset, and the slope $(\beta)$. Lines (3) through (6) are the prior distributions (described as mean, standard deviation) for the overall intercept, the slope, the participant-specific intercept, and the participant-specific standard deviation.

Before modeling relationships between ALHB scores and behavior frequencies, I modeled relationships between behavior frequencies and (1) whether or not a clip was recorded during a weekend (17:00 Friday to 24:00 Sunday, or during a school holiday) and (2) the participant's sex. These were treated as dummy variables, with weekend and female coded as 1 , while weekday and male were coded as 0 . Class attendance, alone among all analyzed behaviors, was assumed to be possible only during weekdays (see Table 1). Weekend is a nuisance variable in the context of the present study. Sex, however, is a theoretically noteworthy variable, in that women generally pursue slower life history strategies than men (Figueredo et al., 2005; Kubinski, Chopik \& Grimm, 2017). Because of the rarity (see Table 2) of two of the recorded behaviors, volunteering and religious service/study, and consequent problems with model performance, clips containing either of these behaviors were summed into a single variable, predicted to be positively associated with the ALHB.

For 61 of the 91 participants $(67 \%), n_{\mathrm{i}}$ (the denominator, i.e. the number of clips in which the behavior could have been observed) comprised all clips in which the participant was compliant and awake for the behaviors social interaction, presence at amusement venues, TV and movie watching, videogame playing and the aggregated religious services/volunteering category. For the remaining 30 participants, $n_{\mathrm{i}}$ varied across these behavior categories because one or more of these behaviors could not be coded in one or more clips (e.g. the participant was at a bar in which the music was so loud that it was impossible to determine whether he or she was engaged in social interaction). The maximum percentage of a participant's awake/compliant clips that was subtracted from the total for such an adjustment was 6.6\%. See Data S1 for more details.

Each model generated by these procedures was then compared, using the Widely Applicable Information Criterion, to a null model (i.e. a model of the same behavior containing no predictor variable, only the intercept). Information criteria reward models for explaining more variance in the dependent variable, but penalize models for additional parameters, thus reducing overfitting. The Akaike weights of the compared models sum to 1. A model's weight is an estimate of the probability that the model will make the best predictions on new data, conditional on the set of models considered. For each behavior, all models with Akaike weights greater than that of the null model were then compared, as a single set of models, to each other as well as to the null model. Interpretations took into account both (1) the distribution of a model's estimated value of $\beta$ (i.e. the extent to which its credible interval overlapped zero) and (2) the model's Akaike weight relative to other models predicting that behavior. 
Models were fitted using the Markov chain Monte Carlo estimation engine Stan, via the R Rethinking package (McElreath, 2016; R Core Development Team, 2016; Stan Development Team, 2017).

Because I examined the relationships of many behaviors to the ALHB, correction for multiple tests is necessary. For those behaviors that, based on the procedures described above, appeared to be predicted by the ALHB, I randomly re-assigned the ALHB scores (but no other variables) among the participants and re-ran the models 100 times. I then compared the estimated slopes and Akaike weights of the models based on the real data to the distributions of slopes and Akaike weights generated from these resampled data sets.

\section{Results}

\section{Descriptive statistics}

As reported by Manson (2017a), participants deleted an average of $1.1 \%$ of their audio clips (SD $=2.4 \%$, median $=0$, range $=0-15.0 \%$ ). The mean number of compliant clips per participant was $232(\mathrm{SD}=25.2$, range $=148-261)$. For 43 of the 91 participants $(47.3 \%)$, at least one clip was recorded during a weekend. Of 21,112 compliant clips, 5679 (26.9\%) were recorded during weekends.

Table 1 shows Cohen's kappa for each of the 18 behaviors analyzed. Six behaviors (sighing, talking to kin, and four talk topics) were excluded from further analysis because of inadequate ( $\kappa$ $<.41)$ inter-rater reliability. Table 1 also describes, for each behavior, the relevant denominator, i.e. the set of audio clips in which the behavior could possibly have been observed $\left(n_{\mathrm{i}}\right.$ in the binomial models). Table 2 presents data on the distributions of observed frequencies of each of the 12 behaviors with adequate inter-rater reliability. Five of the behaviors were observed at least once in $>80 \%$ of participants, whereas three behaviors (volunteering, attending religious services or study, and talk endorsing alcohol or recreational drug use) were observed in $<20 \%$ of participants.

Participants rarely went to sleep before the overnight non-recording period began at 24:00. Sixty-seven of 91 (73.6\%) participants were never observed to do so. Among 243 observation days in which participant compliance continued until 24:00, participants were still awake at 24:00 on $209(86.0 \%)$ days. One participant chose to delete all his early morning clips, reducing the sample size to 90 for analyses of daytime sleeping. From these 90 participants, of 4,306 audio clips in which sleeping was recorded, only 338 (7.8\%) were recorded between 18:00 and 24:00.

Four participants, who participated during summer 2014, were dropped from the analysis of predictors of classroom attendance, because inspection of their audio clips and event diaries indicated that there were not enrolled in any classes during the recording period.

As reported in by Manson (2017a), the ALHB's internal reliability (i.e. across its seven scales) was .68. 
340

341

342

343

344

345

346

347

348

349

350

351

352

353

354

355

356

357

358

359

360

361

362

363

364

365

366

367

368

369

370

371

372

373

374

375

376

377

378

\section{Model tests}

Seven behaviors were more frequent during weekends than weekdays. This was evident both in the estimates of $\beta$ (positive, with the $95 \%$ credible interval not including zero), and in comparisons of models using weekend as a predictor to null models of the same behaviors (the former having $100 \%$ of the Akaike weight in all seven cases). These seven behaviors were daytime sleeping, social interaction, proportion of social interactions that involve more than one interlocutor, presence at amusement venues, TV and movie watching, videogame playing, and the aggregated religious services/volunteering category. For these behaviors, models of their associations with ALHB were compared to models including weekend as the only predictor (hereafter, weekend-only models). Only one behavior showed a sex difference, such that the 95\% CI of the estimate of $\beta$ did not include zero, and the model with sex as a predictor had more Akaike weight than the null model. This behavior was videogame playing, which was engaged in more by men than by women $(\beta=-2.76,93 \% \mathrm{CI}=[-4.23,-1.28]$, Akaike weight of predictor model $=84 \%$ ). The model of the relationship between the ALHB and videogame playing were compared to a model in which weekend and sex were the only predictors.

Table 3 shows the results of tests of models using ALHB as a predictor of behavior frequencies. Only one behavior, presence at amusement venues, was associated with ALHB scores (Akaike weight compared to the weekend-only model: 1.00). This association was in the opposite of the predicted direction: people whose ALHB score indicated a slower life history strategy spent more time at amusement venues than those whose ALHB score indicated a faster life history. However, random reassignment of ALHB scores among participants casts doubt on the strength of the relationship. Of the 100 runs of the model with randomly reassigned ALHB scores, six generated positive relationships between ALHB and presence at amusement venues with an Akaike weight of 1.00 compared to the intercept-only model (median estimate of $\beta$ : 1.47). Five other runs generated negative relationships between ALHB and presence at amusement venues with an Akaike weight of 1.00 compared to the intercept-only model (median estimate of $\beta$ : -1.63).

\section{Discussion}

The Arizona Life History Battery (Figueredo 2007), and particularly its 20-item short form the Mini-K, have been widely used for the psychometric assessment of human LHS and have been validated by comparison with other self-report measures (Figueredo et al. 2014a). I examined whether ALHB scores were associated, in theoretically deduced directions, with the frequencies of 12 everyday behaviors of California college students. Results failed to show any power for the ALHB in predicting the frequencies of these behaviors.

Whether these findings undermine confidence in the validity of the ALHB is unclear. It is possible to argue that frequencies of some of the behaviors would not necessarily be expected to reflect LHS variation. For example, because of the proliferation of smartphones and tablets, class attendance by college students may suffer from diminished validity as an indicator of investment 
379

380

381

382

383

384

385

386

387

388

389

390

391

392

393

394

395

396

397

398

399

400

401

402

403

404

405

406

407

408

409

410

411

412

413

414

415

416

417

418 in embodied capital. Audio recordings provide no information about whether a participant in a classroom is paying attention to what's happening in the classroom, as distinct from texting, checking social media, watching video, etc. In contrast, Mehl, Gosling \& Pennebaker (2006), who collected EAR data on college students in the early 2000 s, found that classroom attendance was predicted by self-reported Big Five conscientiousness. As another example, I used daytime sleeping as an indicator of chronotype and hence an indirect indicator of LHS. However, a more valid measure of chronotype would incorporate participants' sleep onset times, which were unknown on $86 \%$ of observation days because of the ethical necessity to include an overnight blackout period in the EAR protocol. Furthermore, six behaviors showed inadequate inter-rater reliability and were therefore not available for analysis. Nevertheless, it is striking that none of the hypothesized behavioral indicators of LHS were associated in the predicted direction with ALHB scores. The ALHB's undercoverage of aspects of extraversion associated with a faster LHS (excitement-seeking, dominance striving; see Del Giudice, 2014; Manson, 2017a) may explain why ALHB scores were not associated as predicted with some of the behaviors listed in Table 1 (e.g. endorsing alcohol or drug use; presence at amusement venues; arguing). It is more surprising that ALHB scores were not associated with behaviors indicative of high extraversion (e.g. social interaction).

The study participants were U.S. college students, as were the participants in most of the studies that have validated the ALHB and Mini-K with respect to other self-report instruments (Figueredo et al. 2014a). The EAR volunteers were in some respects unrepresentative of the student population from which they were drawn, being higher in conscientiousness and lower in emotionality than a sample of students from a course participant pool, at the same university, who did not volunteer for the EAR study (Manson \& Robbins, 2017). However, sample unrepresentativeness is unlikely to account for the null results reported here, because the EAR volunteers did not differ from the participant pool comparison sample with respect to selfreported LHS (e.g. on the 7-point Mini-K, the EAR participants' mean \pm SD was $5.23 \pm .65$, compared to $5.22 \pm .72[\mathrm{~N}=161]$ for the participant pool sample).

A final limitation of the present study is that it examined associations between a stable individual characteristic (life history strategy) and quotidian behavior without accounting for the influence of situations on behavior, or the ways in which individual characteristics, situational characteristics, and behavior interact (de Vries et al., 2016; Rauthmann, Sherman \& Funder, 2015; Sherman, Nave \& Funder, 2010). These processes can be expected to diminish the strength of simple associations between self-reported individual traits and everyday behavior, and may account for the null findings of the present study as well as the paucity of strong associations between self-reported major dimensions of personality and quotidian behavior reported in the EAR study of Mehl, Gosling \& Pennebaker (2006). Ongoing analyses of a subset of the data used here (specifically, audio clips in which participants spoke) are addressing this issue by using other-rated scores on the Riverside Behavioral Q-Sort (Furr, Wagerman \& Funder, 2010) and the Riverside Situational Q-Sort (Wagerman \& Funder, 2009) as a basis for hypothesis testing. 
419 In addition to its substantive findings, the present study illustrates the usefulness of count 420 models (here, binomial regression models) when behavioral observation protocols generate count 421 variables. The common practice of converting counts to proportions unnecessarily discards 422 information helpful to inference (McElreath, 2015). The present study also followed the recent 423 recommendation of some statisticians (McElreath, 2015; McShane et al., 2017) to use 424 alternatives to null hypothesis testing.

\section{Conclusions}

426 This study failed to find relationships between the Arizona Life History Battery and frequencies 427 of 12 of everyday behaviors in U.S. college students. Additional research is necessary to explore 428 the possibility of subtler relationships between psychometrically-assessed life history strategy 429 and quotidian behavior. 
432

433

434

435

436

437

438

439

440

441

442

443

444

445

446

447

448

449

450

451

452

453

454

455

456

457

458

459

460

461

462

463

464

465

466

467

468

469

470

471

472

473

474

475

\section{References}

Adan A, Archer SN, Hidalgo MP, Di Milia L, Natale V, Randler C. 2012. Circadian typology: a comprehensive review. Chronobiology International 29:1153-1175 DOI 10.3109/07420528.2012.719971.

Alisic A, Barrett A, Bowles P, Conroy R, Mehl MR. 2015. Topical review: families coping with chid trauma: a naturalistic observation methodology. Journal of Pediatric Psychology 41:117-127 DOI 10.1093/jpepsy/jsv016.

Baddeley JL, Pennebaker JW, Beevers CG. 2013. Everyday social behavior during a major depressive episode. Social Psychological and Personality Science 4:445-452 DOI 10.1177/1948550612461654.

Barrera M, Jr., Sandler IN, Ramsay TB. 1981. Preliminary development of a scale of social support: studies on college students. American Journal of Community Psychology 9:435447 DOI 10.1007/BF00918174.

Belsky J, Steinberg L, Draper P. 1991. Childhood experience, interpersonal development, and reproductive strategy -- an evolutionary theory of socialization. Child Development 62:647-670 DOI 10.1111/j.1467-8624.1991.tb01558.x.

Brennan KA, Clark CL, Shaver PR. 1998. Self-report measurement of adult attachment: an integrative overview. In: Simpson JA, and Rholes WS, eds. Attachment theory and close relationships. New York: Guilford Press, 46-76.

Brim OG, Baltes PB, Bumpass LL, Cleary PD, Featherman DL, Hazzard WR, Kessler RC, Lachman ME, Markus HR, Marmot MG, Rossi AS, Ryff CD, Shweder RA. 2000. National survey midlife development in the United States (MIDUS). In: DataStat I, and Harvard Medical School DoHCP, editors. Ann Arbor, MI.

Brumbach BH, Figueredo AJ, Ellis BJ. 2009. Effects of harsh and unpredictable environments in adolescence on development of life history strategies: a longitudinal test of an evolutionary model. Human Nature 20:25-51 DOI 10.1007/s12110-009-9059-3.

Buss DM. 1987. Selection, evocation and manipulation. Journal of Personality and Social Psychology 53:1214-1221.

Buss DM. 2009. How can evolutionary psychology explain personality and individual differences? Perspectives on Psychological Science 4:359-366 DOI 10.1111/j.17456924.2009.01138.x.

Charnov EL. 1993. Life history invariants: some explorations of symmetry in evolutionary ecology. Oxford: Oxford University Press.

Chua KJ, Lukaszewski AW, Grant DM, Sng O. 2017. Human life history strategies: calibrated to external or internal cues? Evolutionary Psychology 15 DOI $10.1177 / 1474704916677342$.

de Vries RE, Tybur JM, Pollet TV, Van Vugt M. 2016. Evolution, situational affordances, and the HEXACO model. Evolution and Human Behavior 37:407-421 DOI 10.1016/j.evolhumbehav.2016.04.001.

Del Giudice M. 2014. An evolutionary life history framework for psychopathology. Psychological Inquiry 25:261-300 DOI 10.1080/1047840X.2014.884918.

Dunkel CS, Decker M. 2010. Convergent validty of measures of life-history strategy. Personality and Individual Differences 48:681-684 DOI 10.1016/j.paid.2009.12.014 
476

477

478

479

480

481

482

483

484

485

486

487

488

489

490

491

492

493

494

495

496

497

498

499

500

501

502

503

504

505

506

507

508

509

510

511

512

513

514

515

516

517

518

519

520
Dunkel CS, Summerville LA, Mathes EW, Kesserling SN. 2015. Using the California Q-sort measure of life history strategy to predict sexual behavioral outcomes. Archives of Sexual Behavior 44:1705-1711 DOI 10.1007/s10508-014-0445-5.

Figueredo AJ. 2007. The Arizona Life History Battery. Available at http://www.u.arizona.edu/ ajf/alhb.html.

Figueredo AJ, Cabeza de Baca T, Black CJ, García RA, Ferreira F. HB, Wolf PSA, Woodley MA. 2015. Methodologically sound: evaluating the psychometric approach to the assessment of human life history [Reply to Copping, Campbell, and Muncer, 2014]. Evolutionary Psychology 13:299-338.

Figueredo AJ, Cabeza de Baca T, Woodley MA. 2013. The measurement of human life history strategy. Personality and Individual Differences 55:251-255 DOI 10.1016/j.paid.2012.04.033.

Figueredo AJ, Vásquez G, Brumbach BH, Schneider SMR. 2004. The heritability of life history strategy: the K-factor, covitality, and personality. Social Biology 51:121-143 DOI 10.1080/19485565.2004.9989090.

Figueredo AJ, Vásquez G, Brumbach BH, Schneider SMR. 2007. The K-factor, covitality, and personality: a psychometric test of life history theory. Human Nature 18:47-73 DOI 10.1007/BF02820846

Figueredo AJ, Vásquez G, Brumbach BH, Sefcek JA, Kirsner BR, Jacobs WJ. 2005. The Kfactor: individual differences in life history strategy. Personality and Individual Differences 39:1349-1360 DOI 10.1016/j.paid.2005.06.009

Figueredo AJ, Wolf PSA, Olderbak S, Gladden PR, Fernandes HBF, Wenner C, Hill D, Andrzejczak DJ, Sisco MM, Jacobs WJ, Hohman ZJ. 2014a. The psychometric assessment of human life history strategy: a meta-analytic construct validation. Evolutionary Behavioral Sciences 8:148-185 DOI 10.1037/h0099837.

Funder DC. 2001. Personality. Annual Review of Psychology 52:197-221 DOI 10.1146/annurev.psych.52.1.197

Funder DC. 2012. Accurate personality judgment. Current Directions in Psychological Science 21:177-182 DOI 10.1177/0963721412445309

Furr RM. 2009. Personality psychology as a truly behavioural science. European Journal of Personality 23:369-401 DOI 10.1002/per.724.

Furr RM, Wagerman SA, Funder DC. 2010. Personality as manifest in behavior: direct behavioral observation using the revised Riverside Behavioral Q-Sort (RBQ-3.0). In: Agnew CR, Carlston DE, Graziano WG, and Kelly JR, eds. Then a miracle occurs: focusing on behavior in social psychological theory and research. New York: Oxford University Press, 186-204.

Gladden PR, Figueredo AJ, Jacobs WJ. 2009. Life history strategy, psychopathic attitudes, personality, and general intelligence. Personality and Individual Differences 46:270-275 DOI 10.1016/j.paid.2008.10.010.

Griskevicius V, Tybur JM, Delton AW, Robertson TE. 2011. The influence of mortality and socioeconomic status on risk and delayed rewards: a life history theory approach. Journal of Personality and Social Psychology 100:1015-1026 DOI 10.1037/a0022403.

Kaplan H, Hill K, Lancaster J, Hurtado AM. 2000. A theory of human life history evolution: Diet, intelligence, and longevity. Evolutionary Anthropology 9:156-185 DOI 10.1002/1520-6505(2000)9:4<156::AID-EVAN5>3.0.CO;2-7. 
521

522

523

524

525

526

527

528

529

530

531

532

533

534

535

536

537

538

539

540

541

542

543

544

545

546

547

548

549

550

551

552

553

554

555

556

557

558

559

560

561

562

563

564

Kubinski JS, Chopik WJ, Grimm KJ. 2017. Change across the lifespan in a psychological measure of life history strategy. Evolution and Human Behavior 38:434-441 DOI 10.1016/j.evolhumbehav.2017.04.005.

Landis JR, Koch GG. 1977. The measurement of observer agreement for categorical data. Biometrics 33:159-174.

MacArthur RH, Wilson EO. 1967. The Theory of Island Biogeography. Princeton: Princeton University Press.

Manson JH. 2015. Life history strategy and the HEXACO personality dimensions. Evolutionary Psychology 13:48-66.

Manson JH. 2017a. Are extraversion and openness indicators of a slow life history strategy? Evolution and Human Behavior 38:552-560 DOI 10.1016/j.evolhumbehav.2017.01.005.

Manson JH. 2017b. Life history strategy and everyday word use. Evolutionary Psychological Science DOI 10.1007/s40806-017-0119-3.

Manson JH, Robbins ML. 2017. New evaluation of the electronically activated recorder (EAR): obtrusiveness, compliance, and participant self-selection effects. Frontiers in Psychology 8:658 DOI 10.3389/fpsyg.2017.00658.

McElreath R. 2015. Statistical rethinking: a Bayesian course with examples in $R$ and Stan. Boca Raton, FL: Chapman \& Hall/CRC Press.

McElreath, R. 2016. Rethinking: an R package for fitting and manipulating Bayesian models (Version 1.56). Retrieved from http://xcelab.net/R/rethinking_package.pdf

McShane BB, Gal D, Gelman A, Robert C, Tackett JL. 2017. Abandon statistical significance. arXiv Preprint arXiv:1709.07588.

Mehl MR, Gosling SD, Pennebaker JW. 2006. Personality in its natural habitat: manifestations and implicit folk theories of personality in daily life. Journal of Personality and Social Psychology 90:862-877 DOI 10.1037/0022-3514.90.5.862.

Mehl MR, Pennebaker JW. 2003. The sounds of social life: a psychometric analysis of students' daily social environments and natural conversations. Journal of Personality and Social Psychology 84:857-870 DOI 10.1037/0022-3514.84.4.857.

Mehl MR, Pennebaker JW, Crow DM, Dabbs J, Price JH. 2001. The electronically activated recorder (EAR): a device for sampling naturalistic daily activities and conversations. Behavior Research Methods, Instruments, and Computers 33:517-523.

Mehl MR, Robbins ML. 2012. Naturalistic observation sampling: the electronically activated recorder (EAR). In: Mehl MR, and Conner TS, eds. Handbook of research methods for studying daily life. New York: Guildford, 176-192.

Mehl MR, Robbins ML, grosse Deters F. 2012. Naturalistic observation of health-relevant social processes: the electronically activated recorder methodology in psychosomatics. Psychosomatic Medicine 74:410-417 DOI 10.1097/PSY.0b013e3182545470.

Nettle D. 2010. Dying young and living fast: variation in life history across English neighborhoods. Behavioral Ecology 21:387-395 DOI 10.1093/beheco/arp202.

Nettle D, Penke L. 2010. Personality: bridging the literatures from human psychology and behavioural ecology. Philosophical Transactions of the Royal Society of London Series B: Biological Sciences 365:4043-4050 DOI 10.1098/rstb.2010.0061.

Patch EA, Figueredo AJ. 2017. Childhood stress, life history, psychopathy, and sociosexuality. Personality and Individual Differences 115:108-113 DOI 10.1016/j.paid.2016.04.023. 
565

566

567

568

569

570

571

572

573

574

575

576

577

578

579

580

581

582

583

584

585

586

587

588

589

590

591

592

593

594

595

596

597

598

599

600

601

602

603

604

605

606

607

608

609

Pepper GV, Corby DH, Bamber R, Smith H, Wong N, Nettle D. 2017. The influence of mortality and socioeconomic status on risk and delayed rewards: a repliction with British participants. PeerJ 5:e3580 DOI 10.7717/peerj.3580.

Pianka ER. 1970. On r- and K-selection. American Naturalist 104:592-596.

Ponzi D, Henry A, Kubicki K, Nickels N, Wilson MC, Maestripieri D. 2015. The slow and fast life histories of early birds and night owls: their future- or present-orientation accounts for their sexually monogamous or promiscuous tendencies. Evolution and Human Behavior 36:117-122 DOI 10.1016/j.evolhumbehav.2014.09.008.

R Core Team. 2016. R: A language and environment for statistical computing (version 3.3.0). Vienna, Austria: R Foundation for Statistical Computing. Retrieved from https://www.rproject.org/

Rauthmann JF, Sherman RA, Funder DC. 2015. Principles of situation research: towards a better understanding of psychological situations. European Journal of Personality 29:363-381 DOI 10.1002/per.1994.

Reis HT. 2008. Reinvigorating the concept of situation in social psychology. Personality and Social Psychology Review 12:311-329 DOI 10.1177/1088868308321721.

Richardson GB, Sanning BK, Lai MHC, Copping LT, Hardesty PH, Kruger DJ. 2017. On the psychometric study of human life history strategies: state of the science and evidence of two independent dimensions. Evolutionary Psychology 15 DOI 10.1177/1474704916666840.

Robbins ML, Mehl MR, Holleran SE, Kasle S. 2011. Naturalistically observed sighing and depression in rheumatoid arthritis patients: a preliminary study. Health Psychology 30:129-133 DOI 10.1037/a0021558.

Roth WT. 2005. Physiological markers for anxiety: panic disorder and phobias. International Journal of Psychophysiology 58:190-198 DOI 10.1016/j.ijpsycho.2005.01.015.

Rushton JP. 1985. Differential K Theory: The sociobiology of individual and group differences. Personality \& Individual Differences 6:441-452 DOI 10.1016/0191-8869(85)90137-0.

Sherman RA, Figueredo AJ, Funder DC. 2013. The behavioral correlates of overall and distinctive life history strategy. Journal of Personality and Social Psychology 105:873888 DOI 10.1037/a0033772.

Sherman RA, Nave CS, Funder D. 2010. Situational similarity and personality predict behavioral consistency. Journal of Personality and Social Psychology 99:330-343 DOI 10.1037/a0019796.

Slatcher, RB, Trentacosta CJ. 2012. Influences of parent and child negative emotionality on young children's everyday behaviors. Emotion 12:932-942 DOI 10.1037/a0027148.

Stan Development Team. 2017. RStan: the R interface to Stan. (version 2.15.1). Retrieved from http://mc-stan.org/

Stearns SC. 1992. The evolution of life histories. Oxford: Oxford University Press.

Strouts PH, Brase GL, Dillon HM. 2016. Personality and evolutionary strategies: the relationships between HEXACO traits, mate value, life history strategy, and sociosexuality. Personality and Individual Differences 115:128-132 DOI 10.1016/j.paid.2016.03.047.

Tooby J, Cosmides L. 1990. On the universality of human nature and the uniqueness of the individual: The role of genetics and adaptation. Journal of Personality 58:17-67 DOI 10.1111/j.1467-6494.1990.tb00907.x. 
610

611

612

613

614

615

616

617

618

619

620

621

622

623

624

625

626

627
Verweij KJH, Yang J, Lahti J, Veijola J, Hintsanen M, Pulkki-Råback L, Heinonen K, Pouta A, Pesonen A-K, Widen E, Taanila A, Isohanni M, Miettunen J, Palotie A, Penke L, Service SK, Heath AC, Montgomery GW, Raitakari O, Kähönen M, Viikari J, Räikkönen, Eriksson JG, Keltikangas-Järvinen L, Lehtimäki T, Martin NG, Järvelin M-R, Visscher PM, Keller MC, Zietsch BP. 2012. Maintenance of genetic variation in human personality: testing evolutionary models by estimating heritability due to common causal variants and investigating the effect of distant inbreeding. Evolution 66:3238-3251 DOI 10.1111/j.1558-5646.2012.01679.x

Wagerman SA, Funder DC. 2009. Situations. In: Corr PJ, and Mathews G, eds. Cambridge handbook of personality. Cambridge: Cambridge University Press, 27-42.

Walker R, Gurven M, Hill K, Migliano A, Chagnon NA, de Souza R, Djurovic G, Hames R, Hurtado AM, Kaplan H, Kramer K, Oliver WJ, Vallegia C, Yamauchi T. 2006. Growth rates and life histories in twenty-two small-scale societies. American Journal of Human Biology 18:295-311 DOI 10.1002/ajhb.20510.

Wenner CJ, Bianchi J, Figueredo AJ, Rushton JP, Jacobs WJ. 2013. Life History theory and social deviance: the mediating role of executive function. Intelligence 41:102-113 DOI 10.1016/j.intell.2012.11.004 


\section{Table 1 (on next page)}

Coded behaviors.

Behaviors with kappa $<.41$ were excluded from further analysis. 
1

\begin{tabular}{|c|c|c|c|}
\hline Behavior & $\begin{array}{l}\text { Predicted association with } \\
\text { ALHB }\end{array}$ & $\begin{array}{l}\text { Cohen's } \\
\text { kappa }\end{array}$ & $\begin{array}{l}\text { Denominator ( } n_{\mathrm{i}} \text { in binomial } \\
\text { regression models) }\end{array}$ \\
\hline Sleeping between 06:00 and 18:00 & Negative & .76 & Clips recorded 06:00-18:00 \\
\hline Social interaction (including by phone, Skype, etc.) & Positive & .85 & Clips awake \\
\hline Interactions including $>1$ interlocutor & Positive & .76 & Clips in social interaction \\
\hline Attending class & Positive & .88 & Weekdays 08:00-17:00 \\
\hline Watching TV, movie or video & Negative & .73 & Clips awake \\
\hline Videogame playing & Negative & .52 & Clips awake \\
\hline At amusement venue (bar, concert, athletic event) & Negative & .84 & Clips awake \\
\hline Religious service or study group & Positive & .65 & Clips awake \\
\hline Volunteer service & Positive & .61 & Clips awake \\
\hline Arguing (disagreement accompanied by anger) & Negative & .49 & Clips in which P speaks \\
\hline Talk about future plans ( $>1$ year from present) & Positive & .80 & Clips in which P speaks \\
\hline Talk about past experiences ( $>1$ year ago) & Positive & .30 & N.A. \\
\hline Talk approvingly about alcohol or recreational drug use & Negative & .60 & Clips in which P speaks \\
\hline Talk about kin & Positive & .39 & N.A. \\
\hline Talk to kin & Positive & .17 & N.A. \\
\hline General complaining & Negative & .39 & N.A. \\
\hline Anti-authority talk & Negative & .11 & N.A. \\
\hline Sighing & Negative & .26 & N.A. \\
\hline
\end{tabular}




\section{Table 2 (on next page)}

Observed frequencies of behaviors.

For definitions of possible clips for each behavior, see Table 1. 


\begin{tabular}{|c|c|c|c|}
\hline \multirow[t]{2}{*}{ Behavior } & \multicolumn{2}{|c|}{$\begin{array}{l}\text { Proportion of possible clips in } \\
\text { which behavior was observed }\end{array}$} & \multirow[b]{2}{*}{$\begin{array}{c}\text { Proportion of participants } \\
\text { observed to engage in behavior }\end{array}$} \\
\hline & Mean \pm SD & Range & \\
\hline Sleeping between 06:00 and 18:00 & $.278 \pm .130$ & $.000-.744$ & .99 \\
\hline Social interaction (including by phone, Skype, etc.) & $.323 \pm .166$ & $.022-.731$ & 1.00 \\
\hline Interactions including $>1$ interlocutor & $.391 \pm .182$ & $.000-.800$ & .98 \\
\hline Attending class & $.196 \pm .143$ & $.000-.702$ & .86 \\
\hline Watching TV, movie or video & $.076 \pm .096$ & $.000-.433$ & .88 \\
\hline Videogame playing & $.020 \pm .059$ & $.000-.353$ & .31 \\
\hline At amusement venue (bar, concert, athletic event) & $.013 \pm .030$ & $.000-.137$ & .20 \\
\hline Religious service or study group & $.007 \pm .025$ & $.000-.157$ & .13 \\
\hline Volunteer service & $.008 \pm .026$ & $.000-.151$ & .14 \\
\hline Arguing (disagreement accompanied by anger) & $.013 \pm .034$ & $.000-.250$ & .31 \\
\hline Talk about future plans ( $>1$ year from present) & $.015 \pm .025$ & $.000-.105$ & .41 \\
\hline Talk approvingly about alcohol or recreational drug use & $.005 \pm .015$ & $.000-.103$ & .15 \\
\hline
\end{tabular}




\section{Table 3 (on next page)}

Results of Bayesian aggregated binomial regression analyses of associations between ALHB and behaviors.

Each row represents one model. Intercepts can be converted to estimated proportions by using the inverse link function logistic. Akaike weights are in comparison to appropriate null model (weekend as the only predictor, weekend plus sex as predictors, intercept only) as indicated in the left-hand column. Estimated $ß[95 \% \mathrm{Cl}]$ of sex as a predictor of videogame playing: $-2.90[-4.40,-1.49]$. 


\begin{tabular}{|l|c|c|c|c|}
\hline Behavior & & Predictor $\beta[95 \%$ credible interval] & Akaike weight \\
& $\alpha \pm \mathrm{SD}$ & Weekend & ALHB & $\begin{array}{c}\text { ALHB+weekend compared to } \\
\text { weekend only }\end{array}$ \\
\hline Daytime sleeping & & & .44 \\
\hline Social interaction & $-1.35 \pm .07$ & $1.97[.95,1.19]$ & $-.18[-.42, .07]$ & .55 \\
\hline$>1$ interlocutor & $-1.05 \pm .10$ & $.62[.51, .74]$ & $.19[-.11, .52]$ & .51 \\
\hline Amusement venue & $-.69 \pm .11$ & $.66[.46, .86]$ & $.25[-.10, .60]$ & 1.00 \\
\hline Religious service + volunteer & $-8.32 \pm .66$ & $1.16[.68,1.63]$ & $1.46[-.22,3.02]$ & .00 \\
\hline TV, movie, and video watching & $-7.95 \pm .61$ & $1.45[.84,2.05]$ & $.56[-.91,2.06]$ & .38 \\
\hline & & $.78[.58, .98]$ & $-.06[-.65, .51]$ & ALHB+weekend+sex compared to \\
& & & & weekend+sex only \\
\hline Videogame playing & $-6.09 \pm .53$ & $1.70[1.26$, & $-.06[-1.38,1.24]$ & .00 \\
\hline & & $2.16]$ & & ALHB compared to intercept only \\
\hline Attending class & & N.A. & $.13[-.29, .54]$ & .50 \\
\hline Arguing & $-1.65 \pm .13$ & N.A. & $-.61[-1.31, .06]$ & .05 \\
\hline Talk about future plans & $-4.92 \pm .26$ & N.A. & $-.21[-.80, .38]$ & .06 \\
\hline Talk endorsing alcohol or drugs & $-6.49 \pm .21 \pm .57$ & N.A. & $0.10[-1.07,1.17]$ & .00 \\
\hline
\end{tabular}

5 Videogame femaleness beta: -2.90 [-4.40, -1.49] 